\title{
Adult patient care plan: Management of the febrile neutropenic cancer patient on an outpatient basis
}

\author{
Coleman Rotstein MD FRCPC ${ }^{1}$, Eric J Bow MD MSc DBact FRCPC ${ }^{2}$ \\ and The Febrile Neutropenia Care Plan Working Group*
}

\begin{abstract}
C Rotstein, EJ Bow and The Febrile Neutropenia Care Plan Working Group. Adult patient care plan: Management of the febrile neutropenic cancer patient on an outpatient basis. Can J Infect Dis 2000;11(Suppl D):27D-33D.

Invasive infection may complicate the course of neutropenic cancer patients receiving intensive chemotherapy. The rate of complications is related to prognostic factors including the underlying malignant diagnosis, the state of responsiveness of the underlying disease to treatment, the dose-intensity of the cytotoxic therapy, the duration of neutropenia, the performance status of the patient and comorbid conditions. The pathogens involved are usually the patients' endogenous microflora, and the sites of infection are those anatomic sites colonized with the endogenous microflora. The approach to the febrile neutropenic episode requires a sequence of steps including the recognition of the febrile state (oral temperature higher than $38^{\circ} \mathrm{C}$ ), the depth and duration of the neutropenia (absolute neutrophil count less than $0.5 \times 10^{9} / \mathrm{L}$ ), the identification of a clinical focus of infection and a potential pathogen, the administration of empirical antibacterial therapy, and finally, an assessment of the outcome. Management decisions about whether to treat with oral or parenteral antibacterial agents, with a combination or single agent therapy, or as an inpatient or an outpatient can be based on an assessments of risks of the severity of the patient's comorbid conditions and the patient's risk of developing medical complications that would require inpatient management. The duration of antimicrobial treatment depends on the recovery from the state of neutropenia and the origin of the infectious process.
\end{abstract}

Key Words: Cancer empirical therapy; Fever; Infection; Neutropenia; Prophylaxis; Risk assessment

\section{Plan de soins chez le patient adulte : traitement du cancer neutropénique fébrile en clinique ambulatoire}

RÉSUMÉ : Une infection invasive peut compliquer l'évolution du cancer neutropénique chez les patients sous chimiothérapie intensive. Le taux de complications a trait aux facteurs pronostiques, notamment le diagnostic de néoplasie sous-jacente, sa réponse au traitement, l'intensité de la dose de chimiothérapie cytotoxique, la durée de la neutropénie, le rendement fonctionnel du patient et les comorbidités. Les organismes pathogènes en cause sont habituellement ceux de la microflore endogène du patient et les foyers infectieux sont les sites anatomiques colonisés par cette microflore. L'approche face à l'épisode neutropénique fébrile repose sur une séquence d'étapes, soit reconnaissance de l'état fébrile

voir page suivante

\footnotetext{
${ }^{1}$ McMaster University; Division of Infectious Diseases, Henderson Site, Hamilton Health Sciences Corporation, Hamilton, Ontario;

${ }^{2}$ Departments of Internal Medicine and Medical Microbiology, Sections of Infectious Diseases and Haematology/Oncology;

Head, Section of Haematology/Oncology, The University of Manitoba; and Department of Medical Oncology and Haematology,

CancerCare Manitoba, Winnepeg, Manitoba

*Dr Doug Malyuk, Royal Columbian Hospital, New Westminster, British Columbia; Dr Jamie Maclntyre, Health Sciences Centre, St John's, Newfoundland; Mr Edward Hughes; Ms Glenna Germaine, St Boniface General Hospital, Winnipeg, Manitoba; Ms Janet Templeton, Health Sciences Centre, St John's, Newfoundland; Ms Ann McDonald, The Moncton Hospital, Moncton, New Brunswick; Dr Stephen Landis, General Site, Hamilton Health Sciences Corporation, Hamilton, Ontario; Dr Vivian Lee, North York General Hospital, North York, Ontario; Mr Chris Mitchell, Collingwood General Hospital, Collingwood, Ontario; Ms Maureen Clarke, CORAM, Whitby, Ontario

Correspondence: Dr Eric Bow, Health Sciences Centre, 600-820 Sherbrook Street, Winnipeg, Manitoba R3A 1R9. Telephone 204-787-3964, fax204-787-3115,ebow@hsc.mb.ca
} 

rieure à $0,5 \times 10 \% / \mathrm{L}$ ), identification d'un foyer infectieux clinique et de l'organisme pathogène potentiel, administration d'une antibiothérapie empirique et finalement, vérification des résultats. La décision de traiter au moyen d'antibactériens par voie orale ou parentérale en association ou en monothérapie ou la décision d'hospitaliser le patient ou de le soigner en clinique externe se fonde sur une évaluation des risques associés à la gravité des comorbidités du patient et au risque que ce dernier encourt à l'égard des complications médicales qui nécessiteraient une hospitalisation. La durée de l'antibiothérapie dépend du rétablissement de la neutropénie et de l'origine du processus infectieux.

$\mathrm{F}$ ever developing during a state of neutropenia is considered a predictor of a potentially life-threatening infection. Experience has taught that failure to treat neutropenia-related infections in a timely manner has a high mortality rate (1). Accordingly, the rapid institution of empirical antibacterial therapy at the first recognition of a febrile neutropenic episode (FNE) has become a standard of practice (2).

Neutropenia has been defined by a peripheral absolute neutrophil count (ANC); the ANC comprises segmented neutrophils and band neutrophils, of less than $1.0 \times 10^{9} / \mathrm{L}$. However, the risk of bacterial infection is significantly increased as the ANC falls below $0.5 \times 10^{9} / \mathrm{L}$. Further, the risk of bacteremic infection is increased as the ANC falls below $0.1 \times 10^{9} / \mathrm{L}$. The risk of infection also increases with the duration of neutropenia. Eighty per cent to $100 \%$ of patients with a cytotoxic therapyinduced ANC of less than $0.5 \times 10^{9} / \mathrm{L}$ that lasts seven days or more can be expected to develop an FNE. In contrast, FNEs will develop in fewer than $10 \%$ of patients with a cytotoxic therapyinduced neutropenic episode lasting less than seven days. Patients receiving intermittent cyclical cytotoxic chemotherapy for malignancy typically have neutropenia (ANC less than $0.5 \times 10^{9} / \mathrm{L}$ ) lasting three to four days, whereas patients undergoing remission-induction therapy for acute myeloid leukemia generally have neutropenia lasting more than 14 days.

The duration of neutropenia and risk of FNE can, to some extent, be predicted by the diagnosis and the cytotoxic regimen (3-5). For example, patients with advanced chronic lymphocytic leukemia, myelodysplastic states or aplastic anemia will have ANCs less than $0.5 \times 10^{9} / \mathrm{L}$ for periods of weeks, if not months. The incidence of FNE may be as low as 1/100 days of severe neutropenia. In contrast, patients treated with combination chemotherapy for non-Hodgkin's lymphoma using cyclophosphamide, doxorubicin, vincristine and prednisone may experience three or more FNEs/100 days of treatment, assuming a 10\% rate of FNEs/cycle of treatment and a median of three days in which the ANC is less than $0.5 \times 10^{9} / \mathrm{L} /$ cycle. Further, this rate may be higher than $10 \mathrm{FNEs} / 100$ days among patients receiving myeloablative therapy. These examples differ in the severity of nonhematological toxicities that affect integumental barrier integrity independent of neutropenia. Cytotoxic therapies damage the committed progenitor cells of the mucosal surfaces, leading to barrier disruption. The magnitude and severity of the damage is, to a large extent, correlated with specific classes of chemotherapeutic agents and the dose-intensity of the cytotoxic regimen.

\section{ETIOLOGY}

The majority of neutropenia-related infections are derived from the pool of endogenous microorganisms that normally colonize the mucosal surfaces of the body. Patients with in- dwelling, externalized central venous access devices are at a higher risk for infections due to cutaneous microflora such as the coagulase-negative (eg, Staphylococcus epidermidis) or coagulase-positive (eg, Staphylococcus aureus) staphylococci or Corynebacteria species. Patients receiving antimetabolites that cause oral mucositis, such as methotrexate, fluorouracil or cytarabine, are at a higher risk for invasive infection due to viridans group streptococci such as Streptococcus mitis or Streptocococcus oralis (6). Patients receiving agents that damage the intestinal mucosal surfaces are at risk of infection due to the resident colonizing enteric microflora such as Escherichia coli, Klebsiella species, $S$ aureus or hospital-acquired pathogens such as Pseudomonas aeruginosa (7). Invasive fungal infections are more likely when intestinal epithelial surfaces are damaged by cytotoxic therapy and patients have become colonized by opportunistic yeasts (8) or filamentous fungi.

The spectrum of pathogens associated with communityacquired FNEs may be different than that of nosocomial FNEs, and may include infections due to Mycoplasma pneumoniae, Chlamydia species, Streptococcus pneumoniae or respiratory viruses such as influenza A or B, parainfluenza types 1,2 or 3, adenoviruses, or respiratory syncytial virus.

\section{EVALUATION OF FEBRILE NEUTROPENIC PATIENTS}

FNEs may be classified as microbiologically documented (bacteremic or nonbacteremic) if a pathogen is isolated from a site or focus of infection; as clinically documented if a site of infection is identified without the isolation of the putative pathogen; or as an unexplained fever if neither a site of infection nor pathogen is identified. Many unexplained fevers may prove to be noninfectious fevers.

The clinical evaluation (Table 1) of FNEs should include a patient history and a physical examination directed toward identifying the circumstances under which the episode developed and locating the potential anatomical site of infection. The circumstances of the FNE should include the documentation of the state of neutropenia, cause of the neutropenia, time course of the neutropenia with respect to the time (in days) from the first day of administration of cytotoxic therapy for the current episode, and regimen used. These points are important for estimating the duration of neutropenia and the risk of mucosa-related, nonhematological toxicities (3). Although the signs and symptoms of inflammation and infection may be muted in severely neutropenic patients, evidence for the presence of focal erythema, swelling and tenderness should be sought. The mucosal surfaces of the upper and lower respiratory tract (including the ears, sinuses and lungs), the upper and lower gastrointestinal tract (including the periodontium, buccal mucosae, oropharynx, esophagus, ab- 
TABLE 1

\begin{tabular}{|c|c|c|}
\hline Suspicion of infection & Investigations & $\begin{array}{l}\text { Assessment for risk of complications } \\
\text { requiring admission to hospital }\end{array}$ \\
\hline $\begin{array}{l}\text { - Fever (oral temperature } \\
\text { higher than } 38^{\circ} \mathrm{C} \text { ) } \\
\text { - Signs of marrow failure } \\
\text { (pallor, petechiae or } \\
\text { ecchymoses, inflammatory } \\
\text { foci) } \\
\text { - Symptoms of marrow failure } \\
\text { (fatigue, bruising or } \\
\text { bleeding, feverishness or } \\
\text { chills) }\end{array}$ & $\begin{array}{l}\text { - History and physical examination to identify potential foci of } \\
\text { infection } \\
\text { Respiratory tract: ears, sinuses, lungs } \\
\text { Gastrointestinal tract: periodontium, oropharynx, esophagus, } \\
\text { abdomen, perianal tissues } \\
\text { Genitourinary tract: dysuria, hematuria } \\
\text { Skin or soft tissues: focal erythema, edema, tenderness } \\
\text { - Complete blood count to identify state of leukopenia, neutropenia } \\
\text { (absolute neutrophil count }<0.5 \times 10^{9} / \mathrm{L} \text { ), anemia (hemoglobin } \\
<140 \mathrm{~g} / \mathrm{L} \text { in males or } 120 \mathrm{~g} / \mathrm{L} \text { in females) and thrombocytopenia } \\
\text { (platelet count }<100 \times 10^{9} / \mathrm{L} \\
\text { - Cultures of blood, } 30 \text { to } 40 \mathrm{~mL} \text { (peripheral and each lumen of } \\
\text { central venous access devices) } \\
\text { - Cultures of respiratory secretions, diarrheal stools and lesions as } \\
\text { appropriate } \\
\text { - Serum electrolytes, blood urea nitrogen, serum creatinine and liver } \\
\text { function tests (aspartate transaminase, alanine transferase, lactate } \\
\text { dehydrogenase, alkaline phosphatase, gamma glutamyl } \\
\text { transferase, total bilirubin) } \\
\text { - Chest radiograph }\end{array}$ & $\begin{array}{l}\text { Lower risk (Talcott group IV) } \\
\text { - Outpatients with responsive malignancies } \\
\text { and no comorbities } \\
\text { - Performance status over } 40 \% \\
\text { - Availability of or access to medical assistance } \\
\text { - Compliance with instructions } \\
\text { - Availability of a caretaker at home } \\
\text { Higher risk (Talcott groups I and II) } \\
\text { - Outpatients with no comorbidities but with } \\
\text { uncontrolled, progressing malignancies } \\
\text { (Talcott group II) } \\
\text { - Outpatients with concurrent comorbidities } \\
\text { - Inalcott group II) } \\
\text { or hematients with hematological malignancies } \\
\text { recipients (Talcott group I) }\end{array}$ \\
\hline
\end{tabular}

domen and perianal tissues), and the genitourinary tract, as well as the skin and soft tissues, are sites that should be examined for evidence of infection.

Investigations should include a complete blood count with hemoglobin, total leukocyte, differential leukocyte and platelet counts; serum electrolytes including sodium, potassium, chloride and total carbon dioxide; estimates of kidney function (blood urea nitrogen and serum creatinine levels); and estimates of liver function (aspartate and alanine transaminases, lactate dehydrogenase, gamma glutamyltransferase, alkaline phosphatase and total bilirubin levels). A chest radiograph is recommended to look for evidence of acute lung infection. Radiographs of other body sites such as the sinuses or the abdomen should be performed as the history or physical examination suggests. Cultures of blood should be performed from all lumens of central venous access devices and from at least one peripheral site, for a total of 30 to $40 \mathrm{~mL}$ of blood. Cultures of other body sites should be performed as suggested by the history and physical examination.

\section{RISK ASSESSMENT FOR OUTPATIENT MANAGEMENT}

Febrile neutropenic patients are a heterogeneous population with respect to the varying probabilities for the patients to develop complications, up to and including death, that may influence the outcome of the FNE. Criteria for assessing such risk in patients with a new onset of FNE have been developed by Talcott and colleagues (9-11) at the Dana Farber Cancer Institute, Boston, Massachusetts. These criteria are for use in cancer patient populations receiving myelosuppressive cytotoxic therapy. Patients presenting with an FNE were divided into four groups, including inpatients receiving intensive cytotoxic therapy for hematological malignancies or hematopoietic stem cell transplant (group I); outpatients with active comorbid medical problems, such as uncontrolled diabetes, hypotension, cardiac failure, bleeding, etc (group II); outpatients with no active comorbidities but with progressive, uncontrolled cancer (group III); and outpatients with responsive cancer but without active comorbidity (group IV). In groups I to III, the risk of developing significant problems that would require hospitalization ranged between $25 \%$ to $40 \%$, and the mortality risk ranged between $12 \%$ and $18 \%$. In contrast, the group IV risk of new morbidity and mortality was only $3 \%$ and $0 \%$, respectively. These observations suggested that group IV patients could safely be targeted for outpatient management. However, further validation studies have suggested that up to one-third of these group IV patients may develop complications requiring hospitalization (11). Accordingly, improvement in the risk assessment can be achieved by requiring additional criteria for determining the suitability of outpatient management. These criteria include short term neutropenia (ANC less than $0.5 \times 10^{9} / \mathrm{L}$ for seven days or less), assurance of compliance, availability or accessibility to medical care, availability of a caretaker at home, and a performance status that implies that the patient is able to care for most daily needs (ie, $40 \%$ to $50 \%)(12,13)$. These patients could be considered to be at low risk for medical complications. These criteria should allow physicians to select patients for whom outpatient management would be safe and effective (Figure 1).

\section{ANTIMICROBIAL CHEMOPROPHYLAXIS}

The application of chemoprophylaxis strategies remains controversial. There are limited clinical circumstances in which chemoprophylaxis has been shown to be effective. For the most part, chemoprophylaxis strategies have been most effective under circumstances in which the neutropenic period is longer than seven to 10 days. Chemoprophylaxis is not recommended for patients with shorter term neutropenia. Antiviral prophylaxis with oral acyclovir has been effective in recipients of allogeneic bone marrow transplants and in acute leukemia patients undergoing intensive remission-induction or consolidation therapy. Quinolone-based prophylaxis has been shown to 


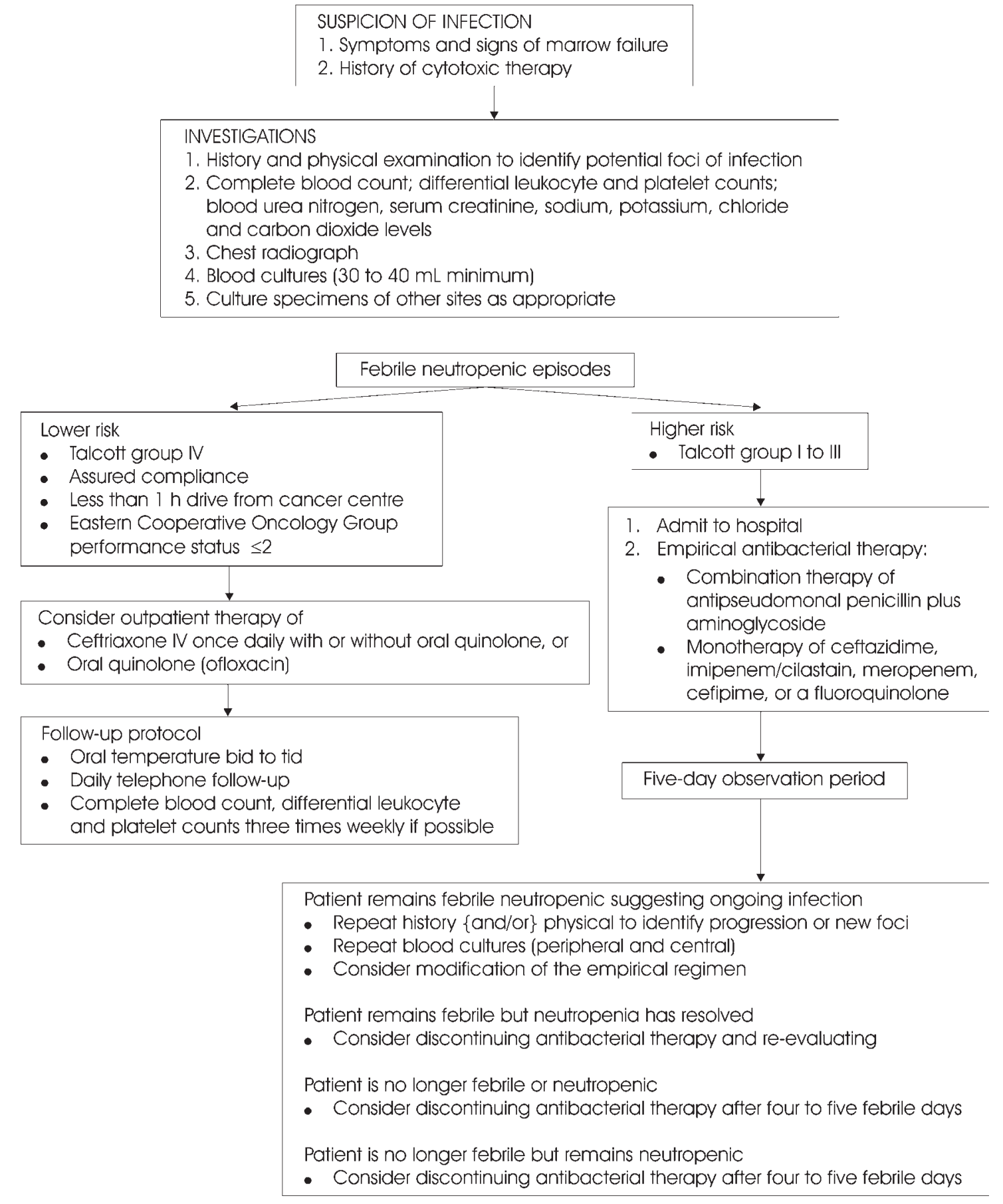

Figure 1) Care plan for febrile neutropenic episodes. IV Intravenous

reduce the risk of febrile morbidity and infection due to aerobic Gram-negative bacilli in these same patient populations (14-16). Similarly, azole-based antifungal prophylaxis has been shown to reduce superficial and invasive fungal infection, and fungal infection-related mortality (17). Treatment effects for antifungal prophylaxis have been demonstrated in patients with acute myeloid leukemia undergoing remissioninduction therapy, with a standard ' $7+3$ '-type regimen with cytarabine and an anthracycline or a high-dose, cytarabine-based regimen, but not for postremission consolidation or acute lymphoblastic leukemia (18). Further, protective benefits have been observed in patients undergoing hematopoietic stem cell allografting or autografting (17), but not in autograft recipients receiving hematopoietic growth factor support concomitantly (18). Overall, antimicrobial prophylaxis treatment effects have not been demonstrated for outpatient populations receiving cytotoxic therapy for lymphoreticular malignanciesor solid tissue malignancies and for patients who have shorter periods of neu- 
TABLE 2

Regimen modification after five days of empirical antibacterial therapy for those with persistent neutropenia-related fever

\begin{tabular}{|c|c|}
\hline Situation & Modification \\
\hline Pathogen not susceptible to the empirical regimen & - Modify according to susceptibility testing \\
\hline Progressive periodontal focus & - Consider metronizadole \\
\hline Ulcerative pharyngitis or mucositis & $\begin{array}{l}\text { - Swab base of ulcer for herpes simplex virus } \\
\text { - Consider acyclovir }\end{array}$ \\
\hline $\begin{array}{l}\text { Pseudomembranous (with or without ulcerative } \\
\text { component) pharyngitis }\end{array}$ & $\begin{array}{l}\text { - Swab for fungal culture and a direct examination for yeasts } \\
\text { - Consider antifungal therapy with oral nystatin followed by ketoconazole or fluconazole } \\
\text { depending on response }\end{array}$ \\
\hline Skin, soft tissue or central venous catheter focus & - Consider vancomycin \\
\hline Diffuse interstitial infiltrates & $\begin{array}{l}\text { - Consider bronchoalveolar lavage (respiratory viruses; herpes simplex viruses; pulmonary } \\
\text { pneumocystosis; chlamydial infection; Legionella species infection) } \\
\text { - Consider trimethoprim/sulphamethoxazole plus erythromycin }\end{array}$ \\
\hline Abdominal or perianal focus & $\begin{array}{l}\text { - Consider Clostridia difficile toxin-related diarrhea, biliary tract infection, diverticular disease, } \\
\text { perirectal soft tissue infection, neutropenicenterocolitis } \\
\text { - Metronidazole should be included }\end{array}$ \\
\hline $\begin{array}{l}\text { Persistent fever with neutropenia despite } \\
\text { antibacterial therapy }\end{array}$ & - Consider empirical antifungal therapy if colonized with fungi \\
\hline
\end{tabular}

tropenia (less than one week). Exceptions to these findings include the use of trimethoprim/sulphamethoxazole for prophylaxis against pulmonary pneumocystosis in patients receiving ProMACE-CytaBOM therapy for non-Hodgkin's lymphoma (19) and during the first two months as antibacterial prophylaxis in patients with newly diagnosed multiple myeloma (20).

\section{EMPIRICAL ANTIBIOTIC THERAPIES}

A variety of effective core regimens are available for the initial management of FNEs, ranging from conventional combination regimens consisting of an antipseudomonal penicillin (ie, carbenicillin, ticarcillin, piperacillin, piperacillin/tazobactam, ticarcillin/clavulanate), or a third- or fourth-generation cephalosporin (ie, ceftriaxone, ceftazidime, cefepime) plus an aminoglycoside (ie, gentamicin, tobramycin, netilmicin, amikacin) or a fluouroquinolone (ie, ciprofloxacin) to monotherapybased regimens consisting of a third-generation cephalosporin (ie, ceftazidime, cefepime, ceftriaxone), a carbapenem (ie, imipenem/cilastatin, meropenem) or a fluoroquinolone (ie, ciprofloxacin or ofloxacin) (Figure 1) (1). Most of these regimens target aerobic, Gram-negative bacilli very effectively; however, frequently, the Gram-positive coverage is suboptimal. Under these circumstances, additional Gram-positive coverage with agents such as the glycopeptides (ie, vancomycin) provides the necessary activity against organisms such as the coagulase-negative staphylococci or enterococci. The role of beta-lactamase inhibitor-containing agents such as piperacillin/tazobactam or ticarcillin/clavulanate as monotherapy in FNE appears promising $(21,22)$. These regimens are administered parenterally. Apart from ceftriaxone and gentamicin, which can be administered intravenously once daily, or cefepime and cefpirome, which can be administered bid, most of these regimens require administration every 6 to $8 \mathrm{~h}$, which is less convenient for outpatient or home use. Parenteral combination and monotherapy regimens have been most effectively applied to patients fitting into risk groups I to III. Group IV low risk patients with neutropenia of short duration (less than seven days) may potentially benefit from orally administered agents with high bioavailability or parenteral, once daily regimens that may facilitate outpatient management and control costs (9-13). A number of trials comprising level I and II evidence (large and small randomized, controlled trials, respectively) have been published that support this kind of approach $(13,23,24)$. The suggestions contained in the accompanying tables and figures are based on these data.

\section{OUTCOME ASSESSMENT}

The primary outcome of a FNE is survival. The next most important outcomes are fever defervescence and resolution of the signs and symptoms of infection. Because defervescence is the only outcome measurable in real time, the success or failure of antibacterial therapy is most often measured on this basis. The median time to defervescence is between four and five days $(2,3)$ from the initiation of the antibacterial regimen, longer than that expected of responding, non-neutropenic patients. In the absence of evidence of progressive infection, fever persisting over the first five days of empirical treatment for an FNE is insufficient to warrant modification of the empirical antibacterial regimen. During this period, evidence for progressing infection should be sought and, if found, should initiate a workup including repeated blood cultures, radiographs where appropriate and cultures of body sites or secretions as appropriate. The disadvantages of regimen modification for fever alone within the first five days include regimen-related toxicities, added costs and, more importantly, added selective pressure for the colonization of the patient with regimen-resistant microorganisms. Recent studies have shown that the risk of fungal colonization and invasion is related to the number of antibacterial regimen modifications in febrile neutropenic patients who have received cytotoxic regimens that damage the intestinal epithelial surfaces (25). The most powerful predictor of response is neutrophil recovery. The median duration of neutropenia (ANC less than $0.5 \times 10^{9} / \mathrm{L}$ ) in patients receiving cytotoxic therapy for solid tissue or lymphoreticular malignancies is three to four days. Accordingly, the rates of defervescence in these patients may exceed $80 \%$ to $90 \%(12)$. 
COPYRIGHT PULSUS GRO GP The rates of response the classification of the FNE and the pathogen. For example, the rates of response for bacteremic infections has been approximately $50 \%$, compared with $60 \%$ to $70 \%$ for clinically documented infections and $70 \%$ to $80 \%$ for unexplained fevers. Infection-related mortality rates have been low, in the range of $5 \%$ to $15 \%$, particularly in the lower risk groups. The response rates for Gram-positive bacteremic episodes treated with regimens targeting Gram-negative pathogens have been lower; however, regimen modifications with agents such as vancomycin have resulted in successful treatment and have prevented infection-related death (26).

\section{REGIMEN MODIFICATION AFTER FIVE DAYS OF EMPIRICAL ANTIBACTERIAL THERAPY}

At day 5 of empirical antibacterial therapy, four possible outcomes can be observed (Figure 1). Patients who have recovered their ANC level to greater than $0.5 \times 10^{9} / \mathrm{L}$ will have become afebrile (that is, they have responded) or they have remained febrile, and warrant re-evaluation and consideration to discontinue antibacterial therapy. Patients who remain neutropenic may have become afebrile (that is, they have responded but remain at risk of subsequent bacterial infection unless antibacterial therapy or prophylaxis is continued until ANC recovery), or they may remain febrile and at higher risk for subsequent infections with resistant microorganisms such as fungi. Such patients should be fully re-evaluated before regimen modification. Finally, another group of patients will remain febrile, although their neutrophil counts will have recovered. It is important to remember that not all neutropenia-related fevers represent infection. Noninfectious fevers include those due to the administration of blood products, hematoma, thrombophlebitis, cytotoxic agents, tissue necrosis and the underlying diagnosis.

Antimicrobial regimen modifications for persistent neutropenia-related fever can be based on clinical findings at the site of infection (Table 2).

Oropharynx-Pseudomembranous pharyngitis: Pseudomembranous pharyngitis suggests the possibility of an opportunistic yeast infection, usually due to Candida species. Exudates on a painful erythematous base may be distributed over the buccal mucosa, tongue surface, soft or hard palate, or gingival surfaces. A calcofluor-stained preparation demonstrates the presence of budding yeasts and pseudohyphae. Microbiological cultures ultimately identify the yeast. Pseudomembranous changes unassociated with these findings argue against fungi as the etiology and suggest that other possibilities such as herpes simplex virus (HSV) infection or cytotoxic therapy-induced mucosal sloughing are more likely. Treatment with topical oral nonabsorbable polyenes such as nystatin suspension (swish and swallow $10^{6}$ units every 4 to $6 \mathrm{~h}$ for five to 10 days) is effective. Many clinicians (and patients) prefer to use the oral azoles such as ketoconazole, fluconazole or itraconazole, which are well tolerated and effective. The factors limiting their efficacy include the erratic and unpredictable absorption of ketoconazole or itraconazole, and the increasing incidence of infection due to nonalbicans Candida species such as Candida glabrata and Candida krusei, which may be fluconazole-resistant.
Ulcerative pharyngitis/gingivitis: Ulcerative phyaryngitis/gingivitis suggests the possibility of HSV infection or mixed anaerobic infection. A rapid enzyme-linked immunoadsorbent assay for HSV can be performed to evaluate this. Cultures obtained from the base of herpetic lesions implanted on human foreskin fibroblast tissue cultures may demonstrate cytopathic effects after three to five days. Treatment with oral acyclovir $200 \mathrm{mg}$ five times daily or $400 \mathrm{mg}$ tid over seven days is an effective regimen. Mixed anaerobic gingivitis is a diagnosis of exclusion because most centres do not employ anaerobic cultures in the investigation of oropharyngeal infection. Metronidazole administered orally or intravenously at $500 \mathrm{mg}$ every $8 \mathrm{~h}$ for five to seven days or clindamycin $600 \mathrm{mg}$ every $8 \mathrm{~h}$ intravenously is not only effective, but it may be diagnostically useful.

Focal abdominal or perirectal pain: Focal abdominal or perirectal pain suggests infection due to resident aerobic and anaerobic enteric microflora, and is more often observed among patients with prolonged cytotoxic therapy-induced myelosuppression. The presence of associated diarrhea with focal abdominal pain in the setting of persistent fever, despite five days of broad spectrum parenteral antibacterial therapy, suggests neutropenic enterocolitis. The median time for this complication to develop is 15 days of chemotherapy (27). The diagnosis can be supported by diagnostic imaging that demonstrates bowel wall thickening and/or associated inflammatory tissue changes such as edema or air-fluid levels. Diarrheal stools should be examined for the presence of Clostridium difficile toxin and, if the patient is an outpatient, for enteric pathogens such as Salmonella species, Shigella species, enterotoxigenic $E$ coli and Campylobacter species. Stools should also be evaluated for parasites such as Giardia lamblia where appropriate. Neutropenic enterocolitis should be treated with broad spectrum antibacterial regimens that are active against obligate anaerobic microorganisms. Metronidazole (500 mg every $8 \mathrm{~h}$ intravenously) may be added to the more standard regimens outlined above. Supportive care with fluids, parenteral nutrition, pain control and blood product support (particularly with platelet concentrates to maintain circulating platelet counts at greater than $10 \times 10^{9} / \mathrm{L}$ to $20 \times 10^{9} / \mathrm{L}$ ). Defervescence may not occur until the marrow has regenerated. Unexplained fever - Empirical antifungal therapy: Persistent fever after day 5 to 7 , despite broad spectrum antibacterial therapy in the setting of gastrointestinal tract colonization by yeasts or new nodular pulmonary infiltrates, suggests the likelihood of invasive fungal infection by opportunistic yeasts and filamentous fungi, respectively. Under these circumstances, the empirical administration of amphotericin B deoxycholate $(0.5$ to $0.8 \mathrm{mg} / \mathrm{kg} /$ day in $5 \%$ dextrose in water infused over 2 to $4 \mathrm{~h}$ ) seems prudent. More recently, studies have suggested that triazoles such as fluconazole or itraconazole may be equally as efficacious and better tolerated. Lipid-based formulations of amphotericin B such as liposomal amphotericin 8 (AmBisome [Fujisawa Inc, Canada]) and amphotericin B lipid complex (Abelcet [Liposome Company Inc, USA]), while expensive, have been shown to be as effective but less nephrotoxic than amphotericin B deoxycholate (28). The efficacy of newer agents such as voriconazole or the echinocandins has not been established in the febrile neutropenic patient population. 
COPYRIG AT PUISUS GRODP Skin and soft tissue infections: Many of the stanaara regl-
mens for the empirical treatment of the febrile neutropenic patient are designed to target Gram-negative microorganisms. Many infections involving the skin and soft tissues, particularly infections associated with central venous access devices, are due to micro-organisms found in the pool of the normal endogenous cutaneous microflora, such as the coagulase-negative staphylococci. Inflammatory changes at the exit site, tunnel site or insertion site of a central venous catheter on day 5 of a course of empirical antibacterial therapy should raise that possibility. After repeated blood cultures through each lumen of the catheter and a peripheral site, vancomycin may be administered (30 $\mathrm{mg} / \mathrm{kg} /$ day in one or two divided doses intravenously).

\section{SUMMARY}

Cancer patients with FNEs are a heterogenous group. At one end of the spectrum are those patients who have prolonged neutropenia after receiving potent myeloablative ther-

\section{REFERENCES}

1. Schimpff SC, Satterlee W, Young VM, Serpick A. Empiric therapy with carbenicillin and gentamicin for febrile patients with cancer and granulocytopenia. N Engl J Med 1971;284:1061-5.

2. Hughes WT, Armstrong D, Bodey GP, et al. 1997 Guidelines for the use of antimicrobial agents in neutropenic patients with unexplained fever. Clin Infect Dis 1997;25:551-73.

3. Bow EJ. Approach to infection in patients receiving cytotaxic chemotherapy for malignancy. In: Hall JB, Schmidt GA, Wood LDH, eds. Principles of Critical Care, 2nd edn. New York: McGraw-Hill Inc, 1998:747-71.

4. Bow EJ. Invasive fungal infections in cancer patients: a Canadian perspective. Curr Oncol1996;3(Suppl 2):S11-5.

5. .Bow EJ. Infection risk and cancer chemotherapy: the impact of the chemotherapeutic regimen in patients with lymphoma and solid tissue malignancies. J Antimicrob Chemother 1998;41(Suppl D):1-5.

6. Bochud PY, Calandra T, Francioli P. Bacteremia due to viridans streptococci in neutropenic patients: a review. Am J Med 1994;97:256-64.

7. Pizzo PA. Management of fever in patients with cancer and treatment-induced neutropenia. N Engl J Med 1993;328:1323-32.

8. Laverdière $\mathrm{M}$, Rotstein $\mathrm{C}$, Bow EJ, Ioannou S, Carr D, Moghaddam $\mathrm{N}$ and the Canadian Fluconazole Study Group. Fungal colonization profiles and subsequent infection in neutropenic patients with cancer: Impact of fluconazole prophylaxis. J Antimicrob Chemother 2000;46:1001-8.

9. Talcott JA, Finberg R, Mayer RJ, Goldman L. The medical course of cancer patients with fever and neutropenia. Clinical identification of a low-risk subgroup at presentation. Arch Intern Med 1988;148:2561-3.

10. Talcott JA, Siegel RID, Finberg R, Goldman L. Risk assessment in cancer patients with fever and neutropenia: a prospective, twocenter validation of a prediction rule. J Clin Oncol 1992;10:316-22.

11. Talcott JA, Whalen A, Clark J, Richer PP, Finberg R. Home antibiotic therapy for low-risk cancer patients with fever and neutropenia: a pilot study of 30 patients based on a validated prediction rule. J Clin Oncol 1997;12:107-14.

12. Rolston KVI, Rubenstein ES, Freifeld A. Early empiric antibiotic therapy for febrile neutropenic patients at low risk. Infect Dis Clin North Am 1996;10:223-37.

13. Rolston KVI. New trends in patient management: risk-based therapy for febrile patients with neutropenia. Clin Infect Dis 1999;29:515-21.

14. Cruciani M, Rampazzo R, Malena M, et al. Prophylaxis with fluoroquinolones for bacterial infections in neutropenic patients: a meta-analysis. Clin Infect Dis 1996;23:795-805.

15. Engels EA, Lau J, Barza M. Efficacy of quinolone prophylaxis in neutropenic cancer patients: a meta-analysis. J Clin Oncol 1998;16:1179-87.

16. Rotstein C, Mandell LA, Goldberg N. Fluoroquinolone prophylaxis
INC. DO NOT COPY W supervision. At the other end of the spectrum are those patients with transient or short-lived neutropenia (less than seven days with their ANC below $0.5 \times 10^{9} / \mathrm{L}$ ) who have no comorbid medical conditions, are self-sufficient, are compliant with medications, have assistance at home and do not have uncontrolled cancer; thus, the patients may be treated as outpatients with either intravenous or oral antimicrobial agents. Care must be taken to identify a focus or site of infection on the basis of history, physical examination and laboratory investigations. Therapy may initially be empirical, but if a microbiologically or clinically documented infection is present, it should be tailored to the implicated pathogen or site of infection.

Outpatient oral or intravenous therapy should be efficacious, possess little toxicity, be easy to administer (ie, once daily therapies are most desirable), be cost effective and prevent the emergence of resistant organisms to ensure a complete recovery of the patient without undesirable complications (28).

for profoundly neutropenic cancer patients: a meta-analysis. Curr Oncol 1997;4(Suppl 2):S2-7.

17. Bow EJ, Laverdière $M$, Lussier $N$, Rotstein $C$, Cheang MS, Ioannou S. Antifungal prophylaxis in neutropenic cancer patients: a meta-analysis of randomized-controlled trials. Blood 1999;94(Suppl 1):339. (Abst)

18. Rotstein C, Bow EJ, Laverdière M, Ioannou S, Carr D, Moghaddam N. Randomized-controlled trial of fluconazole prophylaxis for neutropenic cancer patients: benefit based on purpose and intensity of cytotoxic therapy. Clin Infect Dis 1999;28:331-40.

19. Browne MJ, Hubberd SM, Longo DL, et al. Excess prevalence of Pneumocystis carinii pneumonia in patients treated for lymphoma with combination chemotherapy. Ann Intern Med 1986;104:338-44.

20. Oken MM, Pomeroy C, Weisdorf O, Bennett JM. Prophylactic antibiotics for the prevention of early infections in multiple myeloma. Am J Med 1996;100:624-8.

21. Bauduer F, Cousin T, Boulat $\mathrm{O}$, et al. A randomized prospective multicenter trial of cefpirome vs piperacillin/tazobactam in febrile neutropenia. 39th Interscience Conference on Antimicrobial Agents and Chemotherapy. San Francisco, September 26 to 29, 1999. (Abst)

22. Glasmacher A, Hahn C, Molitor E, et al. A randomized comparison of piperacillin/tazobactam vs ceftriaxone and gentamicin in 172 severely neutropenic patients with hematologic malignancies. 39th Interscience Conference on Antimicrobial Agents and Chemotherapy. San Francisco, September 26-29, 1999. (Abst)

23. Freifeld A, Marchigiani D, Walsh T, et al. A double-blind comparison of empirical oral and intravenous antibiotic therapy for low-risk febrile patients with neutropenia during cancer chemotherapy. N Engl J Med 1999;341:305-11.

24. Kern WV, Cometta A, De Bock R, Langenaeken J, Paesmans M, Gaya $H$. Oral versus intravenous empirical antimicrobial therapy for fever with granulocytopenia who are receiving cancer chemotherapy. N Engl J Med 1999;341:312-8.

25. Bow EJ, Loewen R, Cheang MS, Schacter B. Invasive fungal disease in adults undergoing remission-induction therapy for acute myeloid leukemia: the pathogenetic role of the antileukemia regimen. Clin Infect Dis 1995;21:361-9.

26. Feld R. Vancomycin as part of initial empirical therapy antibiotic therapy for febrile neutropenia in patients with cancer: pros and cons. Clin Infect Dis 1999;29:503-7.

27. Kasper K, Loewen R, Bow E. Neutropenic enterocolitis (NEC) in acute leukemia (AL) patients in Manitoba. Clin Infect Dis 1996;23:866. (Abst)

28. Bow EJ, Laverdière $M$, Rotstein $C$. A systematic review of the efficacy of azoles and lipid-based formulations of amphotericin B or empirical therapy in persistently febrile neutropenic patients despite broad spectrum antibacterial therapy. 40th Interscience Conference on Antimicrobial Agents and Chemotherapy. Toronto, September 17, 2000. (Abst) 


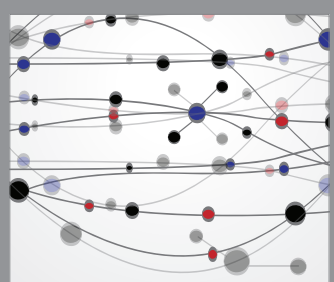

The Scientific World Journal
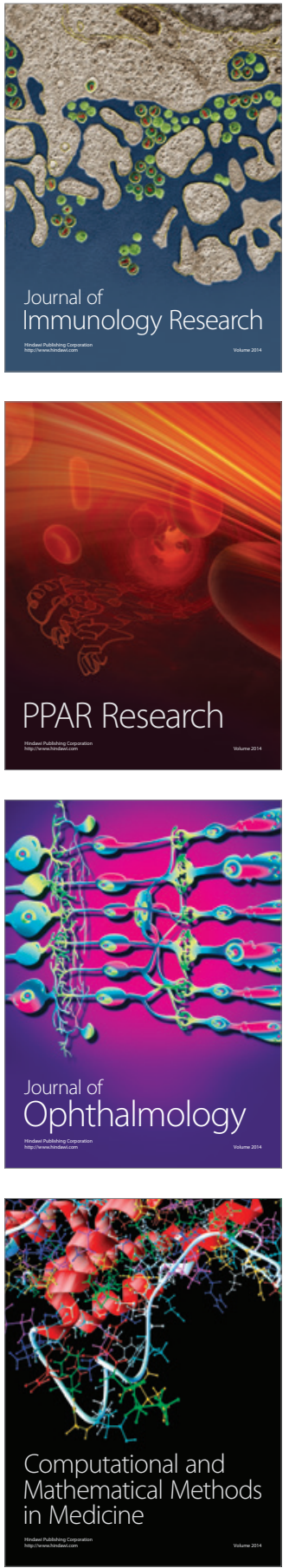

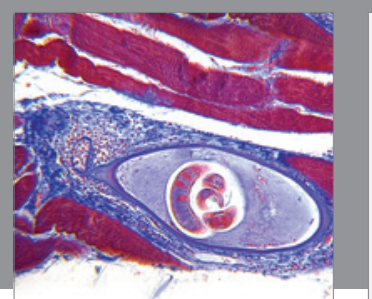

Gastroenterology Research and Practice

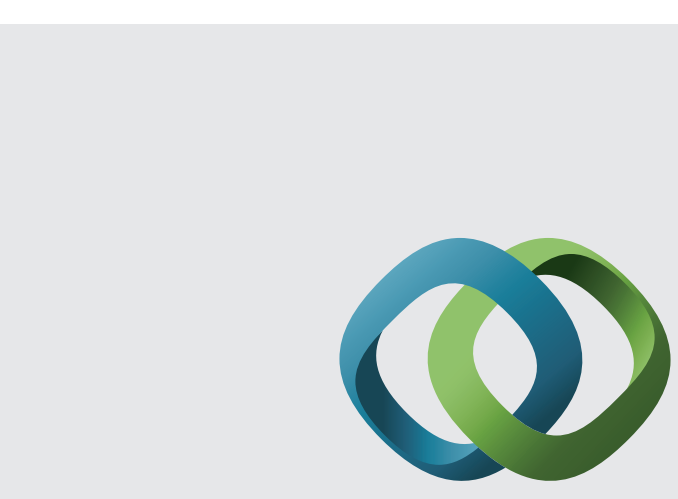

\section{Hindawi}

Submit your manuscripts at

http://www.hindawi.com
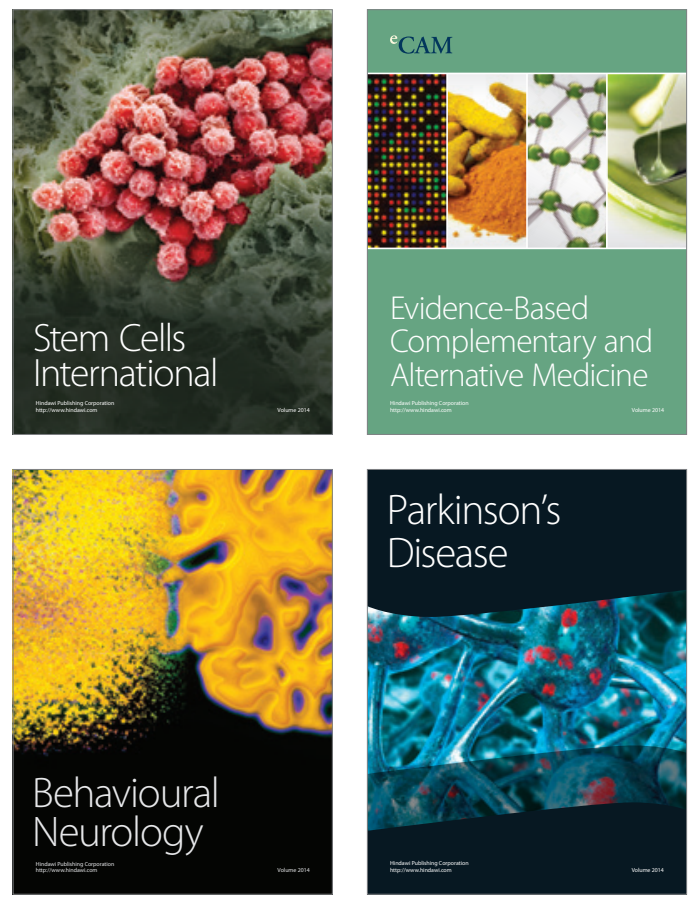
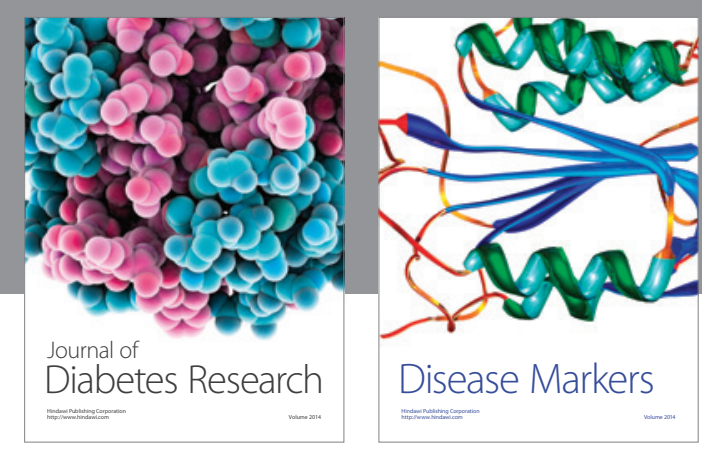

Disease Markers
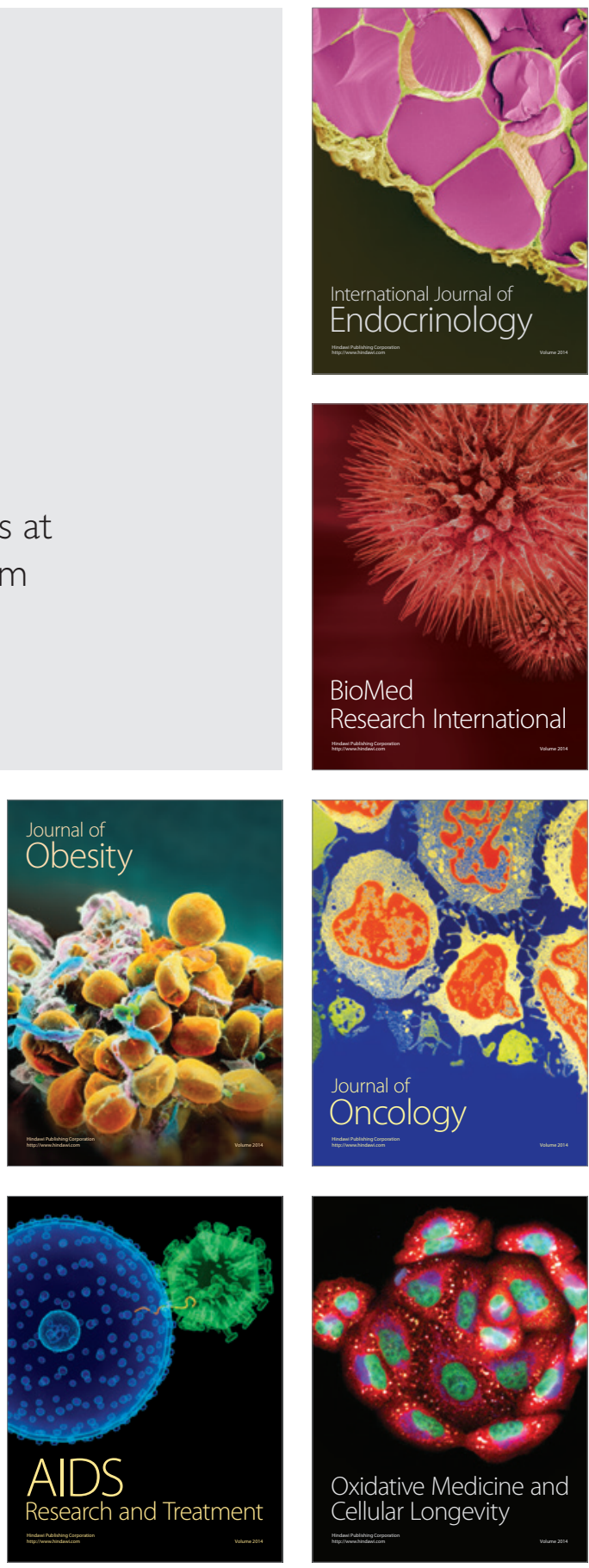